\section{Ларина О.И.}

канд. экон. наук, доцент кафредры банковского дела и предпринимательства ФГБОУ ВО «Государственный университет управления», Москва

e-mail: oi_larina@guu.ru

\section{Larina 0.I.}

Associate Professor at the banking department, Ph.D. in Economics, Associate Professor State University of Management,

Moscow

e-mail: oi_larina@guu.ru

\section{Банковские кризисы: проблемы их идентификации и преодоление}

\section{Аннотация}

В статье исследуются кризисные явления в банковской системе, приводится классисикация банковских кризисов. Банковские кризисы имеют много общих характеристик, но часто их протекание отличается. Они могут различаться по характеру распространения кризисных явлений в национальной экономике, по глубине и остроте, по числу затронутых финансовых институтов, ряду других признаков. Наиболее опасным и разрушительным состоянием является так называемый системный банковский кризис, то есть кризис, затронувший всю национальную банковскую систему. Использованы методы системного анализа, сравнения и кластеризации. Анализируются применяемые в России и за рубежом стратегии преодоления и конкретные антикризисные инструменты, приемлемые при различных состояниях. Идентификация наступившего кризиса необходима для разработки и принятия стратегии его преодоления. Банковские кризисы могут вызывать различные и порой полностью противоречащие друг другу факторы. Практика показывает, что не существует универсальной стратегии нормализации ситуации в банковском секторе, но в любом случае необходимо отметить важность участия государства в процессе преодоления банковских кризисов. При отсутствии государственного вмешательства банковские кризисы имеют серьезные последствия для экономики. Форма участия государства в процессе преодоления банковского кризиса и масштабы вовлечения государства в решение проблем неплатежеспособности банков могут быть различны: государство может ограничиться мерами по стимулированию и организации поддержки частного капитала; предпочесть официальную финансовую поддержку некоторых банков; взять банки под государственный контроль (управление) или ликвидировать часть банков.

\section{Ключевые слова:}

банковский кризис, виды банковских кризисов, преодоление кризиса, стратегия преодоления кризиса, инструменты преодоления кризиса.

\section{Banking Crises: Identification Problems and Resolution}

\begin{abstract}
This article examines crisis developments in the banking system and contains a classification of banking crises. Banking crises have many common characteristics, but often their course is different. They can vary in nature spread of the crisis in the national economy, the depth and severity, the number of affected financial institutions, among other symptoms. The most dangerous and devastating condition is called systemic banking crisis, a crisis that affected the entire national banking system. The author used method of system analysis, method of comparison and clusterization method. We will analyze resolution strategies and specific anti-crisis tools used in Russia and abroad, and applicable to different conditions. Identification of the crisis is needed to develop and adopt strategies to overcome it. Banking crises can cause different and sometimes completely contradictory factors. Practice shows that there is no universal strategy for normalizing the situation in the banking sector, but in any case it is necessary to note the importance of state participation in the process of overcoming the banking crises. In the absence of government intervention banking crises have serious consequences for the economy. The form of state participation in the process of overcoming a banking crisis and the extent of state involvement in solving the problems of insolvency of banks can be different: the government may restrict the measures to promote and support organization of private capital, to prefer the formal financial support of some banks, to take the banks under state control (control) or eliminate part of banks.
\end{abstract}

Keywords:

banking crisis, types of banking crises, crisis resolution, crisis resolution strategy, crisis resolution tools.
В настоящее время экономика любой страны значительным образом связана с ее банковской системой. Банки не только обслуживают платежи предприятий и организаций, кредитуют их нужды, а также хранят и инвестируют свободные ресурсы обслуживаемых клиентов, но их совокупная деятельность влияет на макроэкономические показатели развития каждой отдельной страны.

История каждой отдельной страны хранит свои примеры экономической нестабильности, в том числе сопровождающиеся банковскими кризисами. Феномен кризисов заключается в их неизбежности, обусловленной закономерностями развития рыночной экономики. Данный факт, однако, не отклоняет актуальности исследования кризисных явлений с целью накопления опыта преодоления, систематизации полученных данных для организации своевременного превентивного управления. Исследованиями экономических кризисов занималось значительное количество известных ученых, в том числе Н. Кондратьев, Е. Слуцкий, М. Фридман, Д. Китчин, Э. Хансен и др. Банковские кризисы также являются объектами пристального внимания в последние годы. Так, в работах Б. Бернанке, L. Leven, F. Valen- 
cia (2012, 2010, 2008), G. Hoggarth, J. Reidhill, Sinclair (2004), И. Ковзанадзе (2002), А. Demirguc-Kunt, E. Detragiache (1997) анализируется и систематизируется опыт преодоления банковских кризисов. Вместе с тем динамика и усложнение финансовых операций, а также всеобщая глобализация и изменчивость мира определяют необходимость постоянного поиска и обновления исследований.

Считается, что банкротство некоторых хозяйствующих субъектов является закономерностью рыночной экономики, нормальным явлением, сопутствующим любому виду деятельности. В связи с этим возникают вопросы: закрытие одного банка - это банковский кризис? Что является критерием банковского кризиса?

Отметим, что сокращение количества работающих в стране банков является всеобщим трендом. Проводя анализ сокращения количества банков за 10 лет (2005-2015 гг.), можно заметить, что самым значительным было сокращение количества банков в Индии - на 47\% (с 296 ед. до 157 ед.). Россия по данному показателю находится на втором месте 45\% (с 1249 до 681), на третьем месте США - 30\% (с 7556 до 5304) [7].

Под кризисом (от греч. krisis - решение, поворотный пункт) понимается острое затруднение с чем-либо, тяжелое положение. Исходя из этого, под банковским кризисом понимается острое затруднение в банковской системе, характеризующееся тяжелым положением банков.

Экономическая литература не дает однозначного определения банковского кризиса, поскольку достаточно сложно провести разделение между проблемами группы банков (или даже одного крупного банка) и проблемами банковской системы. Отметим, что кризисы могут быть различной силы и характера действия.
По мнению специалистов Международного валютного фонда, кризис банковской системы характеризуется возникновением в совокупности двух негативных явлений: национальная банковская система сталкивается с крупными потерями (неработающие кредиты составляют около $20 \%$, или при закрытии банков утрачивается не менее $20 \%$ совокупных банковских активов), а также бюджетные затраты на оздоровление банковской системы превышают 5\% ВВП [12].

С точки зрения другого автора, банковский кризис - это стремительное и масштабное ухудшение качества банковских активов под влиянием неблагоприятных факторов макроэкономического, институционального, регулятивного характера [3].

Отметим еще одно мнение, в соответствии с которым банковский кризис представляет собой денежно-кредитный кризис, т.е. кризис, выражающийся в нарушении сбалансированности денежнокредитной системы. Это характеризуется сокращением коммерческого и банковского кредита, массовыми изъятиями вкладов и крахами банков, погоней за наличными деньгами и золотом, падением курсов акций и облигаций, резким повышением нормы процента[1].

Проблема наличия разных точек зрения на определение банковского кризиса приводит к тому, что разные ученые и экономисты учитывают разное количество свершившихся кризисов. Так, в России некоторое время шли дискуссии о 2004 г.: был ли банковский кризис? [4]. И однозначно ответить на этот вопрос до сих пор нельзя в силу разных критериев оценки.

Хотя банковские кризисы имеют достаточно много общих характеристик, часто их протекание отличается. Они могут различаться по характеру распространения кризисных явлений в националь-

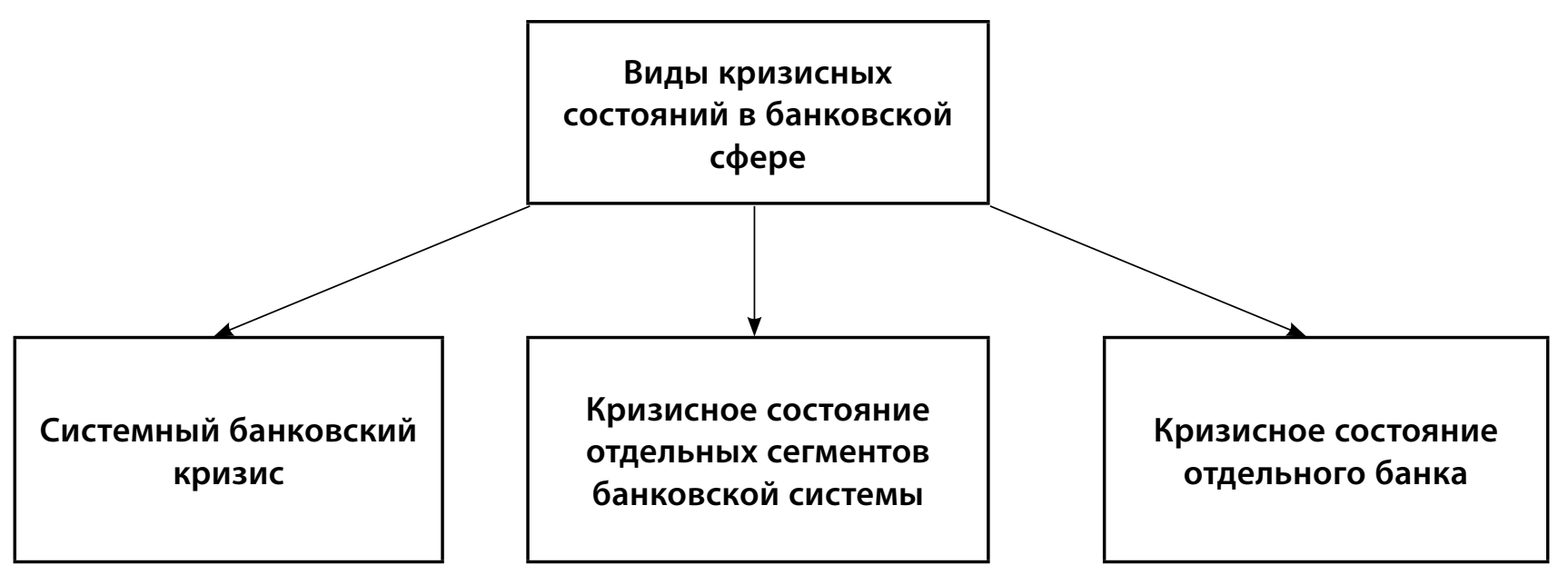

Рис. 1. Виды кризисных состояний в банковской сфере 
Классификация банковских кризисных явлений

\begin{tabular}{|c|c|c|}
\hline $\begin{array}{l}\text { Критерий } \\
\text { классификации }\end{array}$ & Группа по выделенному критерию & $\begin{array}{c}\text { Пример (все примеры составлены автором на основе официальных } \\
\text { пресс-релизов Банка России) }\end{array}$ \\
\hline $\begin{array}{l}\text { По масштабам } \\
\text { охвата }\end{array}$ & $\begin{array}{l}\text { локальный банковский кризис - это кризис } \\
\text { отдельного некрупного банка; } \\
\text { региональный банковский кризис - это } \\
\text { кризис банков в рамках одного региона; } \\
\text { системный банковский кризис затрагивает } \\
\text { деятельность банков в масштабах всей } \\
\text { страны или большинства ее регионов; } \\
\text { международный (глобальный) банковский } \\
\text { кризис охватывает банковские системы } \\
\text { нескольких государств }\end{array}$ & $\begin{array}{l}\text { Локальный банковский кризис возникает при банкротстве любого } \\
\text { банка, при этом важно, чтобы негативные последствия этого } \\
\text { кризиса не имели распространения. Так, в } 2016 \text { г. в России был } \\
\text { закрыт (26.09.2016 г. отозвана лицензия на банковские операции) } \\
\text { Военно-промышленный банк (ВПБ). Хотя банк был достаточно } \\
\text { крупным и занимал } 101 \text { место среди банков РФ по величине } \\
\text { активов, а на момент отзыва лицензии в банке находилось более } 29 \\
\text { млрд рублей на вкладах и счетах фрзических лиц, развития кризиса } \\
\text { не последовало. } \\
\text { Примером регионального банковского кризиса можно считать } \\
\text { кризис, разразившийся летом } 2004 \text { г. и затронувший банки } \\
\text { Московского региона РФ. } \\
\text { Яркий пример системного банковского кризиса в РФ был в } 1998 \text { г. } \\
\text { Кризис затронул все регионы и основную массу российских банков, } \\
\text { что привело к необходимости разработки концепции реструктуриза- } \\
\text { ции российской банковской системы. } \\
\text { В 2007-2009 гг. разразился международный (глобальный) банков- } \\
\text { ский кризис, негативные проявления которого были заметны во всех } \\
\text { банковских системах, в том числе и в России }\end{array}$ \\
\hline $\begin{array}{l}\text { По фрорме } \\
\text { проявления } \\
\text { банковских } \\
\text { кризисов }\end{array}$ & $\begin{array}{l}\text { кризисы в открытой форме - когда } \\
\text { большинство банков прекратило проводить } \\
\text { банковские операции; } \\
\text { кризисы в латентной форме - когда } \\
\text { значительная часть банков несостоятельна, } \\
\text { но продолжает пока функционировать }\end{array}$ & $\begin{array}{l}\text { Открытая и скрытая (латентная) фрормы, по сути, взаимосвязаны. } \\
\text { Латентная форма предшествует открытой фроме кризиса. Приме- } \\
\text { ром открытой формы кризиса будет любое свершившееся банкрот- } \\
\text { ство банка. } \\
\text { Пример скрытой фрормы кризиса, не перешедшего в открытую } \\
\text { форму, в российской практике - это санация банка «Траст», которая } \\
\text { велась под контролем Агентства страхования вкладов (далее - АСВ, } \\
\text { государственная корпорация в РФ, функционирует с } 2004 \text { г., имеет } \\
\text { три основные функции: страхование вкладов физических лиц в } \\
\text { банках РФ, санация кризисных банков и проведение в них ликвида- } \\
\text { ционных процедур). Банк «Траст» является одним из крупнейших } \\
\text { российских розничных банков по размеру активов (253,821 млрд } \\
\text { руб. на 31.12.2015). В декабре 2014 г. в ответ на обращение банка } \\
\text { «Траст» в Банк России о предоставлении финансовой поддержки } \\
\text { Банк России принял решение о мерах по фринансовому оздоровле- } \\
\text { нию банка. Частная банковская группа «Открытие» была выбрана } \\
\text { инвестором для проведения санации банка «Траст», на оздоровле- } \\
\text { ние банка выделено } 127 \text { млрд руб. С 23.06.2016 была восстановле- } \\
\text { на нормальная работоспособность «Траста» и прекращено фрунццио- } \\
\text { нирование АСВ в качестве временной администрации банка «Траст» }\end{array}$ \\
\hline $\begin{array}{l}\text { По степени } \\
\text { обособленности } \\
\text { от других } \\
\text { общественных } \\
\text { систем }\end{array}$ & $\begin{array}{l}\text { сугубо банковский кризис или изолирован- } \\
\text { ный банковский кризис, т.е. кризис, } \\
\text { затрагивающий только участников банков- } \\
\text { ского сектора и их клиентов; } \\
\text { банковский кризис, сочетающийся с } \\
\text { общеэкономическим кризисом (иногда в } \\
\text { литературе встречается термин «платежный } \\
\text { кризис»). Характерное проявление кризиса } \\
\text { - задержки с выдачей заработной платы, } \\
\text { что сопровождается ухудшением материаль- } \\
\text { ного положения населения, ограничением } \\
\text { платежеспособного спроса на товары и } \\
\text { услуги. Платежный кризис и вызванное им } \\
\text { уменьшение поступлений доходов в бюджет } \\
\text { оказывают влияние на образование } \\
\text { бюджетного дефицита, что ограничивает } \\
\text { возможность расходования средств } \\
\text { государством. Приводит к использованию в } \\
\text { обороте различных способов других } \\
\text { расчетов: бартера, зачетов, векселей; } \\
\text { банковский кризис, сочетающийся с } \\
\text { валютным кризисом (когда номинальное } \\
\text { обесценение национальной валюты } \\
\text { относительно международной денежной } \\
\text { единицы достигает 25\%); } \\
\text { банковский кризис, сочетающийся с } \\
\text { социально-политическим кризисом }\end{array}$ & 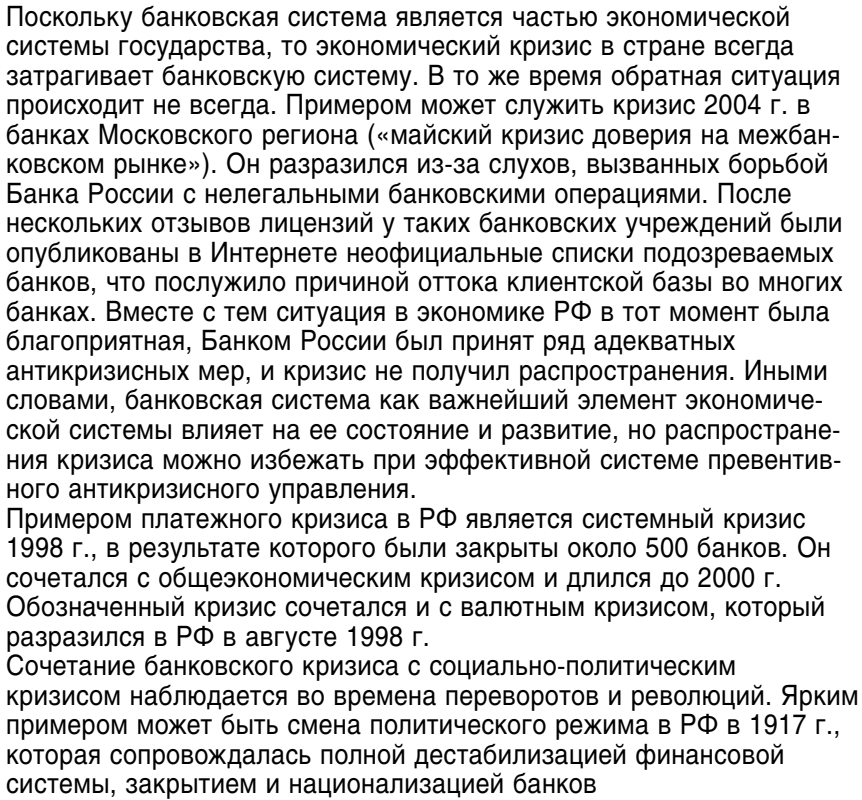 \\
\hline
\end{tabular}




\begin{tabular}{|c|c|c|}
\hline $\begin{array}{l}\text { По источникам, } \\
\text { послужившим } \\
\text { причиной } \\
\text { возникновения } \\
\text { банковского } \\
\text { кризиса }\end{array}$ & $\begin{array}{l}\text { - банковский кризис, вызванный } \\
\text { внутренними по отношению к банков- } \\
\text { ской системе факторами (например, } \\
\text { неэффективное управление в конкрет- } \\
\text { ных банках); } \\
\text { банковский кризис, вызванный } \\
\text { внешними макроэкономическими } \\
\text { факторами (например, падение цен на } \\
\text { рынках, неплатежеспособность } \\
\text { какого-либо сектора экономики и др.); } \\
\text { спровоцированный банковский кризис, } \\
\text { вызванный паникой населения («иноек- } \\
\text { ционный банковский кризис») - когда } \\
\text { закрытие одного крупного банка } \\
\text { порождает недоверие вкладчиков ко } \\
\text { всей банковской системе и вкладчики } \\
\text { осуществляют массовые изьятия своих } \\
\text { вкладов }\end{array}$ & $\begin{array}{l}\text { Многие кризисы вызваны внутренними причинами - неправильными } \\
\text { стратегическими решениями руководства, неадекватным управле- } \\
\text { нием собственными рисками или ошибками и нарушениями } \\
\text { персонала. Так, закрытие } 20.11 .2013 \text { в России «Мастер-банка» } \\
\text { может являться примером данной группы. Банк занимал } 65 \text { место } \\
\text { в России по сумме чистых активов. Глава Банка России Э. Набиул- } \\
\text { лина заявила, что Мастер-Банк был вовлечен в обслуживание } \\
\text { теневой сети экономики, незаконного оборота, неоднократное } \\
\text { нарушение законодательства по борьбе с “отмыванием». } \\
\text { Не редкими бывают и кризисы, вызванные внешними факторами. } \\
\text { Так, обозначенный выше системный банковский кризис 1998 г. в РФ } \\
\text { был вызван экономическим кризисом в сочетании с валютным } \\
\text { кризисом }\end{array}$ \\
\hline $\begin{array}{l}\text { По механизмам } \\
\text { разрешения } \\
\text { банковских } \\
\text { кризисов }\end{array}$ & $\begin{array}{l}\text { - банковские кризисы, ликвидация } \\
\text { которых произошла с использованием } \\
\text { только внутренних механизмов } \\
\text { конкретных банков; } \\
\text { банковские кризисы, ликвидация } \\
\text { которых произошла с использованием } \\
\text { внешней помощи (с использованием } \\
\text { помощи государственных органов) }\end{array}$ & 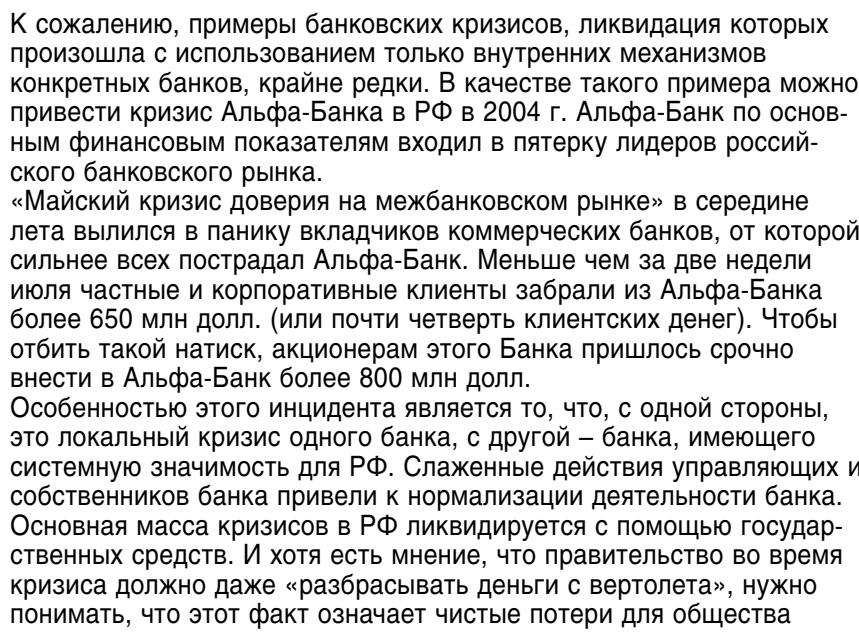 \\
\hline $\begin{array}{l}\text { По периоду } \\
\text { протекания }\end{array}$ & $\begin{array}{ll}\text { - } & \text { краткосрочный банковский кризис - } \\
\text { кризис, разрешаемый в течение } \\
\text { нескольких месяцев (до одного } \\
\text { квартала); } \\
\text { среднесрочный банковский кризис - } \\
\text { продолжительность такого кризиса до } \\
\text { одного года; } \\
\text { долгосрочный банковский кризис - кри- } \\
\text { зис длительностью более одного года }\end{array}$ & $\begin{array}{l}\text { Так, кризис } 2004 \text { г. в банках Московского региона был краткосроч- } \\
\text { ным и завершился в течение } 3 \text { месяцев. } \\
\text { Локальные банковские кризисы, как правило, являются среднесроч- } \\
\text { ными (см. приведенный выше пример банка «Траст»). } \\
\text { Все системные кризисы протекают достаточно длительно, т.е. } \\
\text { являются долгосрочными }\end{array}$ \\
\hline $\begin{array}{l}\text { По имевшим } \\
\text { место послед- } \\
\text { ствиям }\end{array}$ & $\begin{array}{l}\text { - } \quad \text { кризис, не имевший необратимых } \\
\text { последствий, после которого удалось } \\
\text { восстановить деятельность прежних } \\
\text { субъектов; } \\
\text { кризис, в результате которого произош- } \\
\text { ли реорганизации или национализации } \\
\text { банков; } \\
\text { кризис, приведший к необратимым } \\
\text { последствиям, в результате чего часть } \\
\text { банковских организаций была ликвиди- } \\
\text { рована }\end{array}$ & $\begin{array}{l}\text { Наиболее заметными являются кризисы, характеризующиеся } \\
\text { закрытиями банков. } \\
\text { В приведенных примерах также были отражены случаи кризисов с } \\
\text { восстановлением деятельности прежних субъектов. } \\
\text { Примером кризиса с национализацией банков является системный } \\
\text { банковский кризис } 1998 \text { г.: государство с помощью Агентства по } \\
\text { реструктуризации кредитных организаций национализировало ряд } \\
\text { кризисных банков. Еще одним подобным примером в РФ является } \\
\text { Гута-банк (входил в } 2004 \text { г. в тридцатку крупнейших банков в } \\
\text { стране). В июле } 2004 \text { г. он прекратил возврат вкладов и остановил } \\
\text { платежи. Спустя несколько дней его купил Банк «ВТБ» (один из } \\
\text { крупнейших российских банков, контролируемый государством) за } \\
\text { символический } 1 \text { млн руб. }\end{array}$ \\
\hline
\end{tabular}

ной экономике, по глубине и остроте, по числу затронутых финансовых институтов, ряду других признаков. Так, по результатам анализа научных работ и собственного исследования практических данных представим следующую классификацию банковских кризисных явлений (см. табл.1).

На практике реализация банковского кризиса означает, что значительное количество банков в стране не в состоянии выполнять свои обязательства и осуществлять операции, что в дальнейшем приводит к разорению и банкротствам банков. С точки зрения степени охвата кризисными явлениями национальной банковской системы можно выделить несколько видов кризисных состояний (см. рис. 1).

Отметим, что идентификация наступившего кризиса необходима для разработки и принятия стра- 
тегии его преодоления. Наиболее опасным и разрушительным состоянием является так называемый системный банковский кризис, т.е. кризис, затронувший всю национальную банковскую систему (что не означает, однако, что в кризисном состоянии находятся все кредитные организации). Например, мировой финансовый кризис 2007-2009 гг. был примечателен во многих отношениях, являясь и самым дорогостоящим за всю мировую историю, и самым масштабным

Кроме того, отметим появление в «арсенале» регулирующих органов иных антикризисных инструментов:

- стимулирование экономического спроса и поддержка отдельных программ;

- погашение обязательств банков-банкротов в рамках внесудебной процедуры за счет реализации их активов (данная процедура успешно проводилась как в США в рамках так называемых сделок покупки активов и принятия обязательств, так и в России по договору передачи активов и обязательств);

- гарантирование убытков - участие государственных органов в предполагаемых убытках банкаинвестора, которые могут возникнуть в результате покупки банка-банкрота (применялся в США);

- поиск государством инвестора для пострадавшего банка и финансовая помощь инвестору (применялся в России: в рамках санации банка «КИТ Финанс» предоставлялась финансовая помощь инвестору - «Российские Железные Дороги», а также санация приводимого в табл. 1 примера оздоровления банка «Траст»).
Следует учитывать, что в каждом из обозначенных на рис. 1 случаев могут быть пограничные состояния, при которых достаточно сложно однозначно трактовать кризисное явление. Российская практика банковского регулирования и надзора устанавливает четкое и конкретное толкование кризисного состояния отдельного банка [5]. Считается, что банк находится в кризисе, если в его деятельности есть хотя бы одно из нарушений, касающихся выполнения платежных обязательств, а также нарушений экономических нормативов по достаточности капитала и текущей ликвидности.

Вместе с тем нужно учитывать, что трансформация финансового состояния банка не может быть четко регламентирована (см. рис. 2). Достаточно сложно однозначно идентифицировать границы, отделяющие проблемный банк от кризисного банка или стабильный банк от банка, имеющего незначительные текущие проблемы.

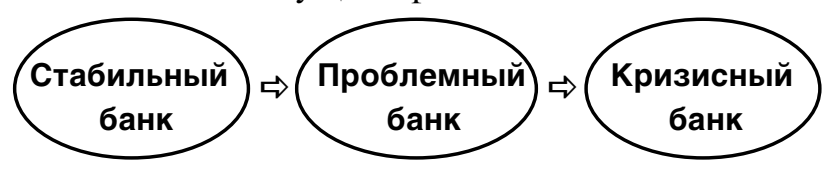

Рис. 2. Трансформация финансового состояния банка

Так, можно взять за основу критерии, определяющие стабильно функционирующий банк. Состояние функционирующего банка признается стабильным, если он не нарушает действующее законодательство, своевременно и в полном объеме проводит все платежи, на рыночных условиях выполняет банковские операции, стабильно выполняет установленные обязательные нормативы, получает нормаль-

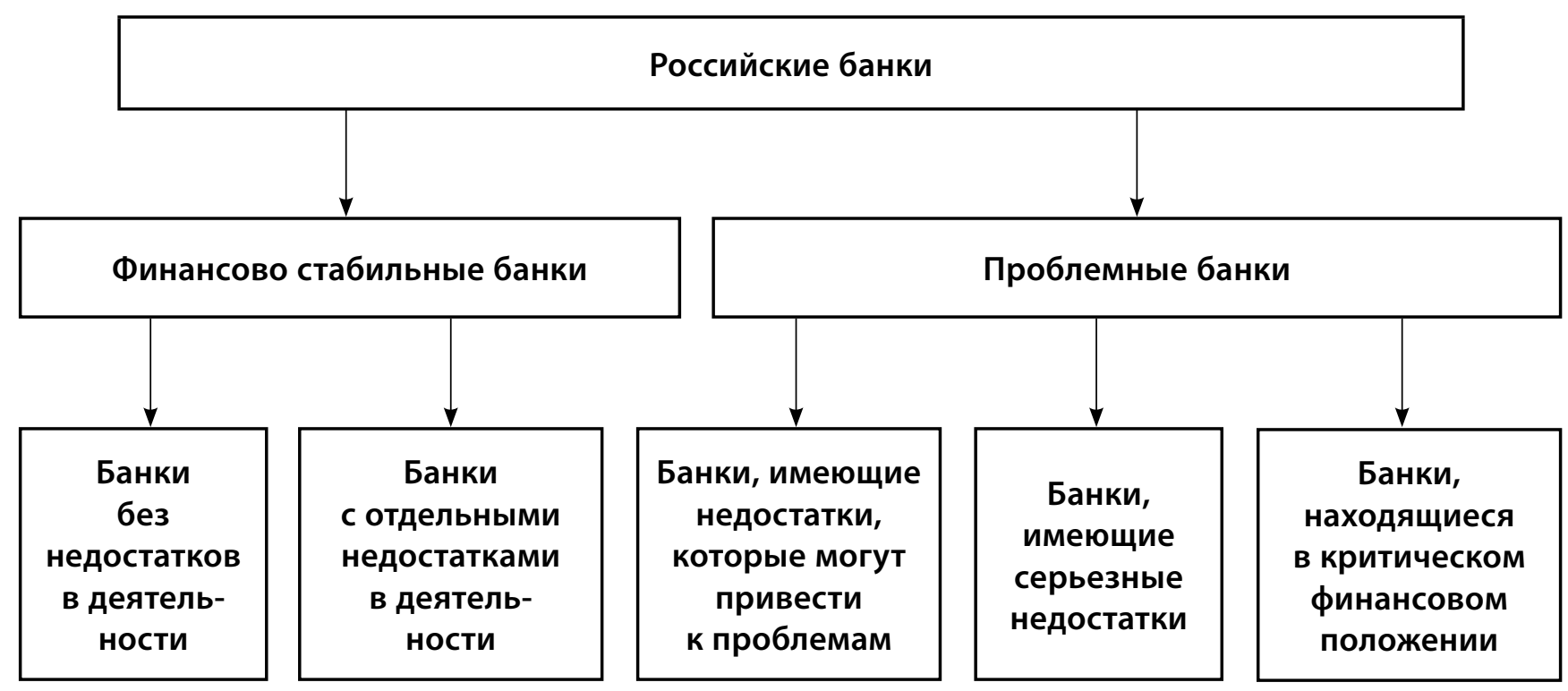

Рис. 3. Группы российских банков с точки зрения их финансовой устойчивости 
ную прибыль, не имеет конфликта интересов внутри организации. Любое отклонение от указанной нормы будет означать, что банк испытывает проблемы разной степени сложности и, следовательно, является проблемным банком. При этом может быть разная степень проблемности банка.

В российской практике банковского надзора данный аспект не регламентируется. В соответствии с действующими нормами надзора под проблемными банками понимаются банки, подлежащие ликвидации (или банки в критическом финансовом положении, т.е. имеющие основания для отзыва банковской лицензии); банки, испытывающие серьезные финансовые трудности (банки, относящиеся к кризисным), а также иные проблемные банки, состояние которых не дифференцируется (см. рис. 3; составлено на основании Указания Банка России от 30 апреля 2008 г. № 2005-У «Об оценке экономического положения банков» [6]).
Таким образом, своевременное обнаружение проблемного банка - вопрос достаточно актуальный, кроме того имеющий не только экономическую, но и социальную подоплеку. Поэтому здесь необходим исключительно ответственный подход. Многие специалисты в последнее время обсуждают проблему и необходимость внедрения системы макропруденциального анализа с целью мониторинга макроэкономической ситуации, выявления дисбалансов в денежно-кредитной сфере и разработки мероприятий по предотвращению так называемых системных рисков. Под основной контроль рекомендуется брать системно значимые банки и предъявлять им особые (или дополнительные) требования. Такая практика нашла применение и в регулировании банковской деятельности в РФ. В то же время целесообразно, на наш взгляд, разработать аналогичный подход в регулировании и регионально значимых банков (чего в России нет).

\section{Литература}

1. Зеленский Ю.Б. Механизмы повышения устойчивости банковской системы [Текст] / Ю.Б. Зеленский, Е.А. Бирюкова // Деньги и кредит. - 2006. - № 7. - С. 11-20.

2. Классики кейнсианства. Т. 2 [Текст] // Хансен Э. Экономические циклы и национальный доход. - М., 1997. - C. 5-23.

3. Ковзанадзе И. Системные банковские кризисы в условиях финансовой глобализации [Текст] / И. Ковзанадзе // Вопросы экономики. - 2002. - № 8. - С. 89-95.

4. Матовников М.Ю. Затянувшаяся реабилитация [Текст] / М.Ю. Матовников // Банковское дело. 2004. - № 11. - C. 9-14.

5. Федеральный закон от 26.10.2002 № 127 «О несостоятельности (банкротстве)» [Электронный ресурс] // URL: http://base.garant.ru (дата обращения: 13.05.2017).

6. Указание Банка России от 30.04.2008 № 2005-У «Об оценке экономического положения банков» [Электронный ресурс] // URL: http://base.garant.ru (дата обращения: 13.05.2017).

7. Тосунян Г. Конференция «Сегодня и завтра банковского сектора России. Факторы формирования уязвимости национального банковского сектора и направления его модернизации» [Текст] / Г. Тосунян // Банковское дело. - 2016. - № 11. - С. 2.

8. Тэйлор А. Глобальные финансы: прошлое и настоящее [Текст] / А. Тэйлор // Финансы и развитие. - 2004. Март. - C. 28-31.

9. Хогарт Г., Рейдхилл Дж., Синклер П. Разрешение банковских кризисов: основные инструменты и издержки [Текст] / Г. Хогарт, Дж. Рейдхилл, П. Синклер // Банки: мировой опыт. - 2004. - № 5.

10. Bernanke B.S., 2010. Implications of the Financial Crisis for Economics. Speech at the Conference Co-sponsored by the Center for Economic Policy Studies.

\section{References}

1. Zelenskiy Yu.B., Biryukova E.A. Mekhanizmy povysheniya ustoychivosti bankovskoy sistemy [Mechanisms of increasing the stability of the banking system]. Den'gi $i$ kredit [Money and credit]. 2006, I. 7, pp. 11-20.

2. Khansen E. Klassiki keynsianstva [Classics of Keynesianism]. Ekonomicheskie tsikly i natsional'nyy dokhod [Economic cycles and national income]. Moscow, 1997, V. 2, pp. 5-23.

3. Kovzanadze I. Sistemnye bankovskie krizisy v usloviyakh finansovoy globalizatsii [Systemic banking crises in the conditions of financial globalization]. Voprosy ekonomiki [Issues of economics]. 2002, I. 8, pp. 89-95.

4. Matovnikov M.Yu. Zatyanuvshayasya reabilitatsiya [Prolonged rehabilitation]. Bankovskoe delo [Banking]. 2004, I. 11, pp. 9-14.

5. O nesostoyatel'nosti (bankrotstve) [On insolvency (bankruptcy)]. Federal'nyy zakon № 127 ot 26.10.2002 [Federal Law No. 127 of October 26, 2002]. Available at: http://base. garant.ru (accessed 13 May 2017).

6. Ob otsenke ekonomicheskogo polozheniya bankov [On assessing the economic situation of banks]. Ukazanie Banka Rossii № 2005-U ot 30.04.2008 [Instruction of the Bank of Russia No. 2005-U of 30.04.2008]. Available at: http://base. garant.ru (accessed 13 May 2017).

7. Tosunyan G. Konferentsiya «Segodnya i zavtra bankovskogo sektora Rossii. Faktory formirovaniya uyazvimosti natsional'nogo bankovskogo sektora i napravleniya ego modernizatsii» [Conference "Today and tomorrow of the Russian banking sector. Factors forming the vulnerability of the national banking sector and the direction of its modernization"]. Bankovskoe delo [Banking]. 2016, I. 11, p. 2.

8. Teylor A., 2004. Global'nye finansy: proshloe i nastoyashchee [Global finance: past and present]. Finansy $i$ razvitie [Finance and Development]. Pp. 28-31.

9. Khogart G., Reydkhill Dzh., Sinkler P. Razreshenie bankovskikh krizisov: osnovnye instrumenty i izderzhki [Reso- 
11. Demirguc-Kunt A., and Detragiache E., 1997. The Determinants of Banking Crises: Evidence from Developing and Developed Countries. IFM Working Paper 106.

12. Leven L., Valencia F., 2010. Resolution of banking Crises: The Good, the Bad and the Ugly. IFM Working Paper 146, p. 36.

13. Leven L., Valencia F., 2012. Systemic Banking Crises Database: An Update. IFM Working Paper 163, p. 33. lution of banking crises: the main tools and costs]. Banki: mirovoy opyt [Banks: world experience]. 2004, I. 5.

10. Bernanke B.S., 2010. Implications of the Financial Crisis for Economics. Speech at the Conference Co-sponsored by the Center for Economic Policy Studies.

11. Demirguc-Kunt A., and Detragiache E., 1997. The Determinants of Banking Crises: Evidence from Developing and Developed Countries. IFM Working Paper 106.

12. Leven L., Valencia F., 2010. Resolution of banking Crises: The Good, the Bad and the Ugly. IFM Working Paper 146, 36.

13. Leven L., Valencia F., 2012. Systemic Banking Crises Database: An Update. IFM Working Paper 163, 33. 